\title{
The Mathematical Space in the Portuguese Language (EMeLP)
}

Fernando Pestana da Costa (Univ. Aberta, Lisboa, Portugal), João Semedo (Univ. de Cabo Verde, Praia, Cape Verde), Marcos Cherinda (UNESCO Office, Maputo, Mozambique), Mário Carneiro (Univ. Federal de Minas Gerais, Belo Horizonte, Brazil), Yuriko Baldin (Univ. Federal de São Carlos, São Carlos, Brazil)

The Mathematical Space in the Portuguese Language (EMeLP - Espaço Matemático em Língua Portuguesa) is an international partnership, the members of which are scientific societies and scientific and academic institutions whose main interest is the promotion and development of mathematics in its broadest sense in countries that have Portuguese as one of their official languages. These countries, located in Africa (Angola, Equatorial Guinea, Cape Verde, Guinea-Bissau, Mozambique, S. Tomé and Principe), America (Brazil), Asia (East Timor) and Europe (Portugal), form a community of more than 260 million, with a broad cultural, historical and social diversity, diverse stages of economic and scientific development, and various needs concerning mathematics teaching and research.

Although the idea to create EMeLP (inspired by the already existing Espace Mathématique Francophone) goes back to the first decade of the 21st century, when it was suggested by Jaime Carvalho e Silva, then the representative of Portugal at the ICMI, real efforts to put the idea on a firm footing only started in January 2014. The founding act of EMeLP took place shortly afterwards, on 7 June 2014, when the then representatives of Brazil (Victor Giraldo), Mozambique (Marcos Cherinda) and Portugal (José Francisco Rodrigues) at the ICMI signed the creation act of EMeLP at IMPA in Rio de Janeiro, Brazil (Figure 1). At present, EMeLP has the active participation of the founding countries and also Cape Verde, which joined the "Space" shortly after. One of our main goals is to invigorate the mathematical community of the remaining Portuguese speaking countries to adhere and get actively involved in EMeLP initiatives.

The objective of EMeLP is to develop and help disseminate, among Portuguese speaking countries, joint

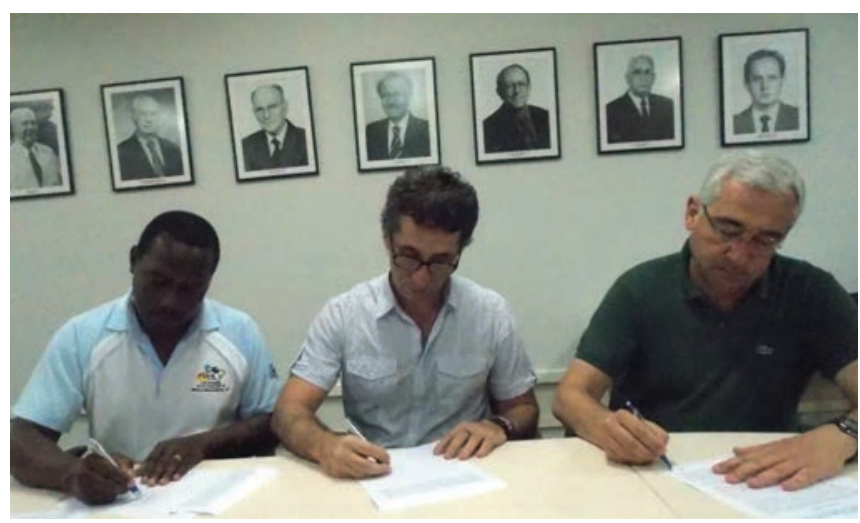

Fig. 1. Signing the creation act of EMeLP in January 2014 in Rio de Janeiro. From left to right: Marcos Cherinda, Victor Giraldo and José Francisco Rodrigues. initiatives in mathematics in its widest sense, namely in: mathematics research; applications of mathematics in other sciences, technology, arts and society at large; education; teacher training; communication and popularisation of mathematics for the general public; and dissemination of educational resources and materials.

Currently, EMeLP publicises its own activities, as well as other mathematics related activities in Portuguese speaking countries, through its Facebook page (https:// www.facebook.com/emelportuguesa); a dedicated webpage is planned for creation soon. However, the first widely visible initiative of EMeLP was the promotion of its 1st international congress (CiEMeLP 2015), which took place in Coimbra, Portugal, 28-31 October 2015, with the moto "The Multiple Ways to Produce and Communicate Mathematical Culture in the Portuguese Language" (Figure 2).

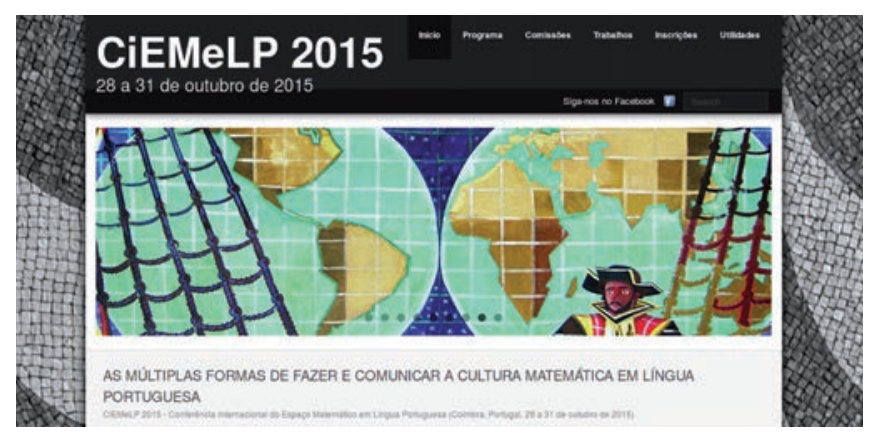

Fig. 2. Webpage of the first international congress of EMeLP, which took place in Coimbra (Portugal), 28-31 October 2015.

This meeting had more than 260 participants from 10 countries (including a few from three countries outside EMeLP - Paraguay, Spain and the UK). There were seven invited plenary talks, two special sessions about the life and work of the late ethnomathematician Paulus Gerdes and the mathematician José Sebastião e Silva, 12 parallel talks and more than 120 contributed talks in the five Discussion Groups ("Mathematics, culture and society", "Relations between mathematics in schools, universities and in other social practices", "Mathematics communication inside and outside schools", "Mathematics' teacher formation" and "Technologies in the teaching and communication of mathematics"), in addition to a significant number of poster presentations. The conference was home to many well-attended and lively discussion sessions, with the participation of mathematicians, mathematical educators and teachers (Figure 3). 


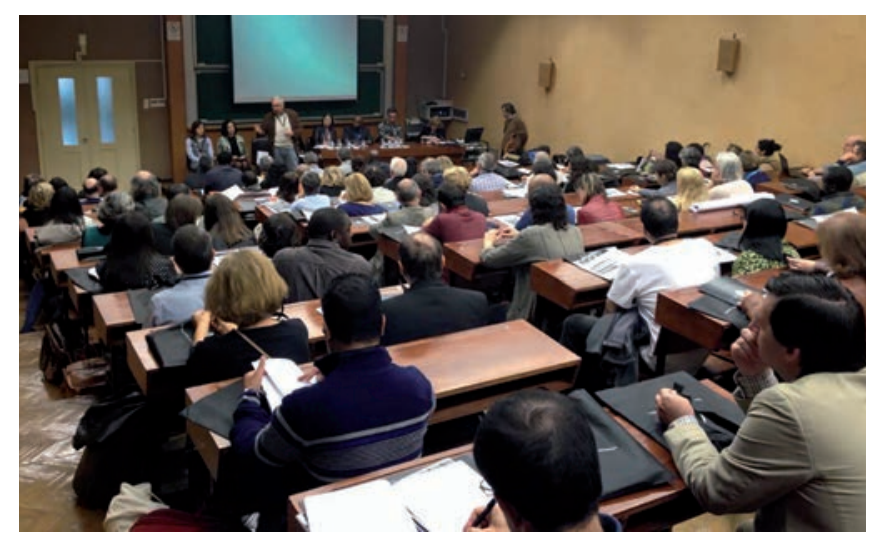

Fig. 3. A panel discussion at the first international congress of EMeLP.

According to the by-laws of EMeLP submitted to the ICMI for approval, these international congresses are to be a regular feature of EMeLP, where discussions of past activities and planning for future initiatives will take place, as well as the election of new direction boards.

The second international congress of EMeLP is scheduled to take place in Maputo, Mozambique, in November 2019.

Although different Portuguese speaking countries have different needs in mathematics education, research and public awareness, and have different cultural contexts in which mathematical practices and reasoning impinge, the need for: public recognition of the importance and ubiquity of mathematics; an improved mathematics education at all levels; a stronger mathematical background for teachers; and improved quality and enhancement of international collaboration and the impact of mathematical research are recognised as important goals in all of the countries involved and, thus, are aspects to which EMeLP will certainly be paying attention in the years to come.

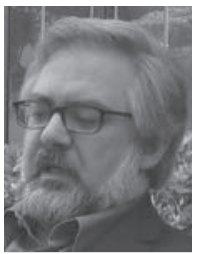

Fernando Pestana da Costa [fcosta@uab. pt] teaches at the Department of Sciences and Technology of Universidade Aberta, Lisbon, and is a researcher at the Centre for Mathematical Analysis, Geometry and Dynamical Systems, Instituto Superior Técnico, University of Lisbon, Portugal. His research interests are in mathematical analysis and differential equations, with a particular emphasis on dynamical aspects. He received his PhD at Heriot-Watt University, Edinburgh, in 1993. He has been Vice-President (20122014) and President (2014-2016) of the Portuguese Mathematical Society. Since 2017, he has been the representative of Portugal at the ICMI.

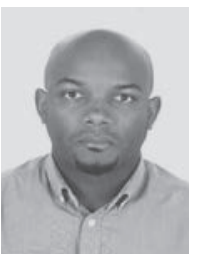

João Felisberto Semedo [joao.semedo@ docente.unicv.edu.cv] is currently the President of the Scientific Council at the University of Cabo Verde. He graduated in mathematics from Universidade Federal Fluminense, Rio de Janeiro (1998), and has an MSc in didactics of mathematics (2004) and a PhD in education (didactics of mathematics), both from Universidade de Lisboa (2011). He is a professor at the University of Cabo Verde and was President of the Pedagogical Council of the Department of Science and Technology and President of its Board of Directors from September 2012 to June 2015. He is a founding member of AMATCV (Mathematical Association of Cape Verde) and is the representative of Cabo Verde at the ICMI.

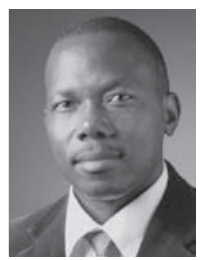

Marcos Cherinda [mcherinda@gmail.com] received the degree of Teacher of Mathematics and Physics (1980-1981) for Secondary Education at the Faculty of Education of Universidade Eduardo Mondlane in Maputo, Mozambique. In 1989, he completed his Diplom Lehrer in mathematics in Germany. In 2002, he received a PhD in mathematics education from the University of the Witwatersrand, Johannesburg, South Africa. Until 2017, he worked as a professor of mathematics education at the Pedagogical University in Mozambique, where he was Director of the Faculty of Natural Sciences and Mathematics. Since 2012, he has been the national representative of Mozambique at the ICMI. He is currently an official of UNESCO at the Maputo office.

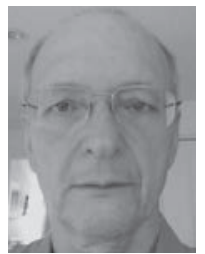

Mário Jorge Dias Carneiro [carneiro@ ufmg.br] is an emeritus professor at Universidade Federal de Minas Gerais, Brazil. His main research area is dynamical systems, with a special interest in conservative systems. He received his PhD from Princeton University in 1980 and has held post-doctoral positions at IMPA, Brazil, and Princeton University. He has been Vice-President of the Brazilian Mathematical Society (1993-1996) and, in 2005, was the coordinator of a curriculum reform in mathematics for the State of Minas Gerais, Brazil. He is the representative of Brazil at the ICMI.

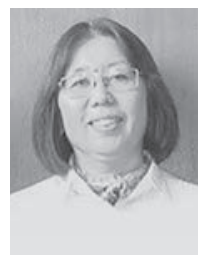

Yuriko Yamamoto Baldin [yuriko@ dm.ufscar.br] received a PhD in mathematics from the Universidade Estadual de Campinas, Brazil, in 1984, with a thesis in differential geometry. She has done postdoctorate studies in the USA, made scientific visits to Japan and has been a visiting professor at the University of Tsukuba (2014). She is a senior professor of mathematics at the Department of Mathematics of the Universidade Federal de São Carlos, where she has worked since 1977. Her research interests include teacher education and development of didactical materials. She has represented Brazil at the ICMI (20082012) and is currently a member at large of the Executive Committee of the ICMI for 2017-2020, after also holding this position for 2013-2016. She is the appointed liaison of EMeLP to the ICMI. 